\title{
Wintering Map for Honey Bee Colonies in El-Behera Governorate, Egypt by using Geographical Information System (GIS)
}

\section{HOSSAM F. ABOU-SHAARA}

\author{
Plant Protection Department, Faculty of Agriculture, Damanhour University, Egypt. \\ email: entomology_20802000@yahoo.com
}

Key words: Honey bees, ArcGIS, suitability, wintering, beekeeping.

\begin{abstract}
ABSTARCT: The geographical information system (GIS) has been used successfully in many studies to solve apicultural problems. The winter season is considered as a challenge for honey bee colonies due to the cold weather which cause the forfeiture of many colonies. The good wintering of honey bee colonies depends mainly on the wintering regions and beekeeping practices. To identify the suitable regions for colonies wintering at El-Behera governorate, different datasets were prepared and spatially analyzed by using ArcGIS. The input datasets were temperature, distance from roads, distance from plants, land cover, slope and precipitation. Two wintering maps were created; all the datasets were combined at the same weight in one map and at different weights in the other map. The two maps showed similarities in their spatial outputs. The suitable areas for colonies wintering were successfully identified. The spatial statistical analysis showed significant differences between the suitable regions and the unsuitable regions. The described model in the present research can be applied elsewhere for the successful identification of suitable wintering regions.@ JASEM
\end{abstract}

\section{http://dx.doi.org/10.4314/jasem.v17i3.9}

Beekeeping is a widespread practice due to the unlimited importance of honey bees. Many problems face honey bee colonies, one of these problems is the cold weather during winter season. The death of many honey bee, Apis mellifera, colonies has been reported during winter season mainly due to the cold weather. The total colony losses in the Belgium for 2008/2009 winter was 19\% (Nguyen, 2010) while for $2011 / 2012$ winter in the USA was $22.5 \%$ (Spleen et al., 2013). Also, colony losses with different percentages has been reported in different countries (see, Nguyen, 2010). The very low temperature can prevent foraging behavior (Joshi and Joshi, 2010) and chill the brood. To solve this critical problem, some researchers have developed modified beehives to protect colonies from the passive impacts of the low temperature (Erdogan et al., 2009; Omran, 2011 \& Zacepins and Stalidzans, 2012). However, such modified beehives are somewhat costly and may need specific requirements (e.g. the availability of electricity source in the apiary).

The geographical information system (GIS) has been applied previously to solve some beekeeping problems and assist in beekeeping development including, the identification of suitable sites for apiaries (Estoque and Murayama, 2010), rangeland suitability for beekeeping (Amiri et al., 2011 \& Amiri and Shariff, 2012), plants suitability for honey bees (Myung-Hee et al., 2001 and Coulson et al., 2005) and for the identification of the suitable regions for beekeeping under harsh environmental conditions of elevated temperature and low relative humidity (Abou-Shaara et al., 2013). Different factors were incorporated into the spatial analysis including; land cover, water resources, roads, slope, temperature and relative humidity to present solution for beekeeping problems (e.g. Amiri et al., 2011 and Abou-Shaara et al., 2013).

In Egypt, as in many parts of the world, many beekeepers suffer from colonies death during winter season. The north of Egypt is rich in cultivated areas and apiaries, especially at El-Behera governorate which is considered as the largest agricultural governorate. However, the identification of the most suitable areas for colonies wintering has not been studied yet. Therefore, the most essential factors impact colonies wintering were incorporated into the spatial analysis to identify the most suitable areas for colonies wintering. Also, two methods for combining datasets were tested and the better method was subsequently recommended in combination with the used model for the successful identification of suitable wintering regions elsewhere.

\section{MATERIALS AND METHODS:}

The study was conducted on El-Behera governorate, a governorate with significance agriculture importance located in the north of Egypt (Fig. 1) with total area of $9826 \mathrm{~km}^{2}$. 


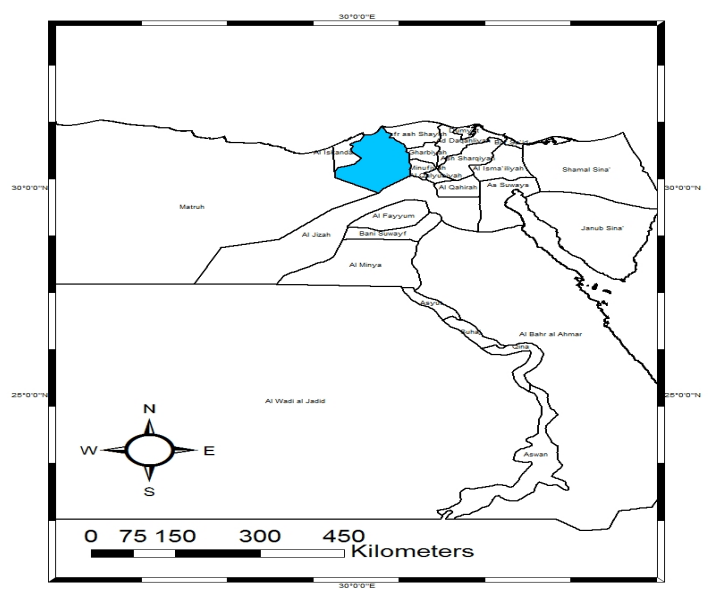

Fig. 1: The location of El-Behera Governorate in the north of Egypt.

The ArcGIS 10 program was employed for the identification of the suitable wintering regions at ElBehera governorate based on the most important factors that impact colonies wintering. The input datasets include; minimum temperature, distance from water resources, distance from roads, slope, land cover, distance from plants and precipitation. The input datasets were prepared as layers for spatial analysis according to Abou-Shaara et al. (2013).

Each dataset (factor) was reclassified according to the importance for colonies wintering as shown in table (1). The minimum temperature was incorporated into the analysis because during the winter season a great decrease in the temperature happens which hinder bee foraging, and a temperature from 10 to $14{ }^{\circ} \mathrm{C}$ was considered as low suitable by Amiri and Shariff, (2012) and Amiri et al. (2011). At the same time the maximum temperature at ElBehera governorate does not excess $26^{\circ} \mathrm{C}$ during winter, and such temperature was considered as suitable for bee colonies (Amiri and Shariff, 2012 \& Amiri et al., 2011) and Tan et al. (2012) found the highest activity of honey bees at the ambient temperature about $20^{\circ} \mathrm{C}$. Therefore, the minimum temperature above $9^{\circ} \mathrm{C}$ was considered as more suitable for wintering in the present model. Although the bees are able to collect water from a relatively long distance about $6 \mathrm{Km}$ (Hagler et al., 2011) and from different resources especially continuous ones (Abou-Shaara, 2012) it is better to locate colonies near to water resources to save forager bee efforts. Thus, the nearest water sources were considered more suitable for wintering than the farther ones. The distance from roads was also considered in the analysis because the near sites from roads are suitable for beekeeping work especially during colonies transportation. Also, the slope was considered in this study because placing the colonies on a relatively even land is better for beekeeping. Accordingly, these factors (distance from roads and slope) were used by Amiri et al., (2011) \& Amiri and Shariff (2012) for studying land suitability for beekeeping.

The land cover was classified into two main categories according to Abou-Shaara et al. (2013). Placing the bee colonies in an area with cultivated plants is much better for honey bee colonies, as some sources for pollen and nectar may exist. Thus, cultivated areas were considered as more suitable. Also, beside the land type, its better to locate the colonies near to the plants. Thus, areas near to plants were considered more suitable. Concerning the precipitation, areas with low precipitation was considered more suitable to protect the colonies from heavy rains.

Table 1: The ranges of input factors and their description.

\begin{tabular}{|l|c|l|}
\hline Datasets & Range & Description \\
\hline \multirow{2}{*}{ Minimum temperature $\left({ }^{\circ} \mathrm{C}\right)$} & $<8$ & Unsuitable \\
\hline \multirow{2}{*}{ Distance from water resources (units)* } & $>9$ & More Suitable \\
\hline \multirow{2}{*}{ Distance from roads (units) } & $0-0.16$ & More Suitable \\
\cline { 2 - 3 } & $>0.16$ & Unsuitable \\
\hline \multirow{2}{*}{ Slope (degrees) } & $0-0.22$ & More Suitable \\
\cline { 2 - 3 } & $>0.22$ & Unsuitable \\
\hline \multirow{2}{*}{ Land cover (types) } & $0-7$ & More Suitable \\
\cline { 2 - 3 } & $7-16$ & Suitable \\
\hline \multirow{2}{*}{ Distance from plants (units) } & $>16$ & Unsuitable \\
\cline { 2 - 3 } & Barren lands & Unsuitable \\
\hline \multirow{2}{*}{ Precipitation (mm) } & Cultivated areas & More Suitable \\
\cline { 2 - 3 } & $>5$ & Suitable \\
\cline { 2 - 3 } & $0-5$ & More Suitable \\
\hline
\end{tabular}

*: units derived from the classified output layers. 
Datasets analysis: Datasets were analyzed by using two methods; 1) the datasets were combined at the same weight of importance for all factors, 2) the datasets were combined at different weights according to their intensity of importance as described by Saaty (2008), table (2) shows the weights of each factor derived from the relative importance matrix. The relative importance value was assigned for each factor based mainly on its importance during winter season. The suitability map for wintering regions resulted from the two methods were compared, and the suitable regions for colonies wintering were recommended. Fig. (2) presents the used model in the study.

Table 2: The derived weights from the relative importance matrix for each variable.

\begin{tabular}{|l|c|c|c|c|c|c|c|}
\hline Variables & A & B & C & D & E & F & G \\
\hline Temperature (A) & 1 & 8 & 5 & 5 & 5 & 2 & 2 \\
\hline Distance from water resources (B) & $1 / 8$ & 1 & 2 & 2 & $1 / 2$ & $1 / 2$ & $1 / 5$ \\
\hline Distance from roads(C) & $1 / 5$ & $1 / 2$ & 1 & 2 & 1 & 1 & $1 / 2$ \\
\hline Slope (D) & $1 / 5$ & $1 / 2$ & $1 / 2$ & 1 & $1 / 4$ & 1 & 1 \\
\hline Land cover (E) & $1 / 5$ & 2 & 1 & 4 & 1 & 1 & 1 \\
\hline Distance from plants (F) & $1 / 2$ & 2 & 1 & 1 & 1 & 1 & 1 \\
\hline Precipitation (G) & $1 / 2$ & 5 & 2 & 1 & 1 & 1 & 1 \\
\hline Derived weights for each variable. & \multicolumn{7}{|c|}{} \\
\hline Variables & A & B & C & D & E & F & G \\
\hline Weights & 0.38 & 0.085 & 0.084 & 0.06 & 0.14 & 0.101 & 0.15 \\
\hline
\end{tabular}

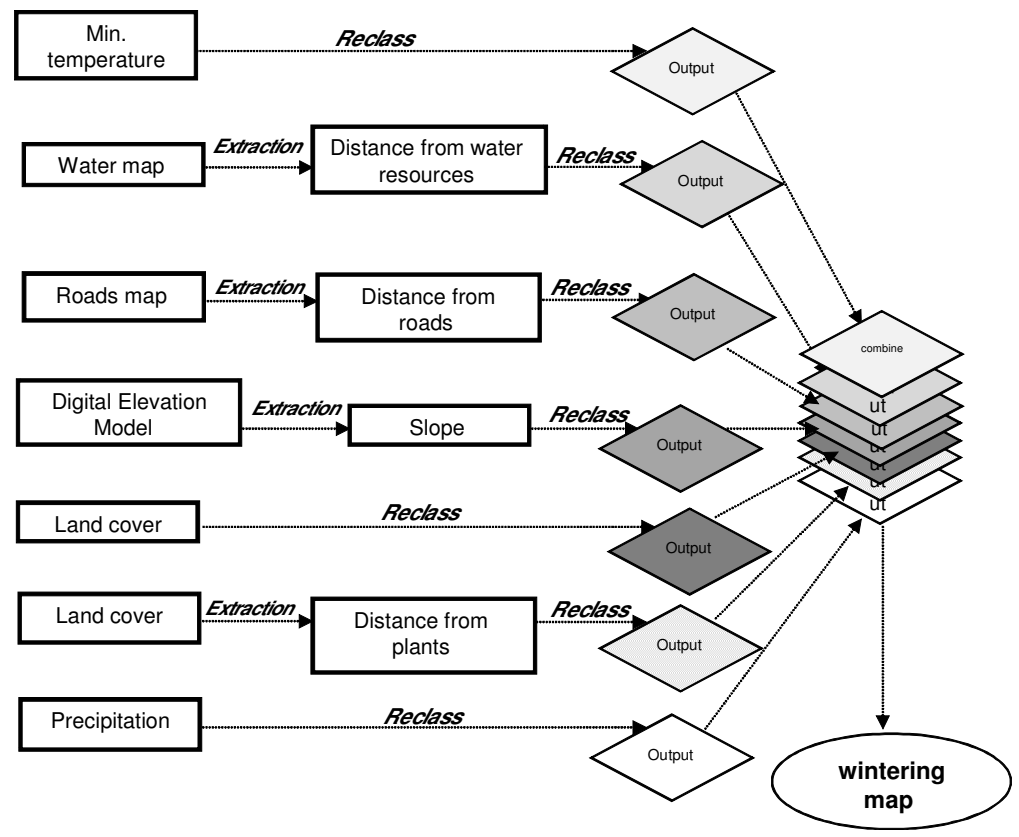

Fig.2: The used model in the study, during the combination step two methods were applied.

Spatial statistical analysis: The classified regions according to their suitability for colonies wintering were statistically analyzed by using the Anselin Local Moran's I statistic at siginificance level of 0.05 according to the $\mathrm{z}$-scores and $p$-values.

\section{RESULTS:}

Fig.3 presents the classified regions according to their wintering suitability for honey bee colonies derived from the combination of input factors at the same weight. The north of El-Behera governorate was classified as more suitable and suitable while the southern regions generally were considered as unsuitable. 


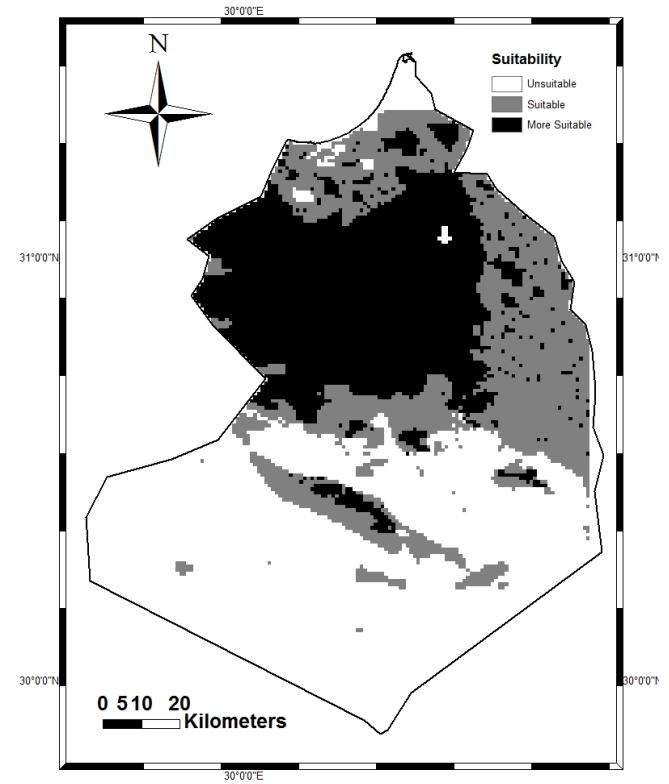

Fig.3. Wintering map derived for different factors at the same weight.

Fig. (4) shows a comparison between the suitable regions for wintering derived from factors at the same weight and an actual map from google earth. To facility the comparison between the two maps a square covering the more suitable wintering regions with specific longitude (X) and latitude (y) as shown in table (3) was added to the two maps. It is clear that the more suitable regions and the suitable regions are located in cultivated regions while the unsuitable regions are located in desert regions.
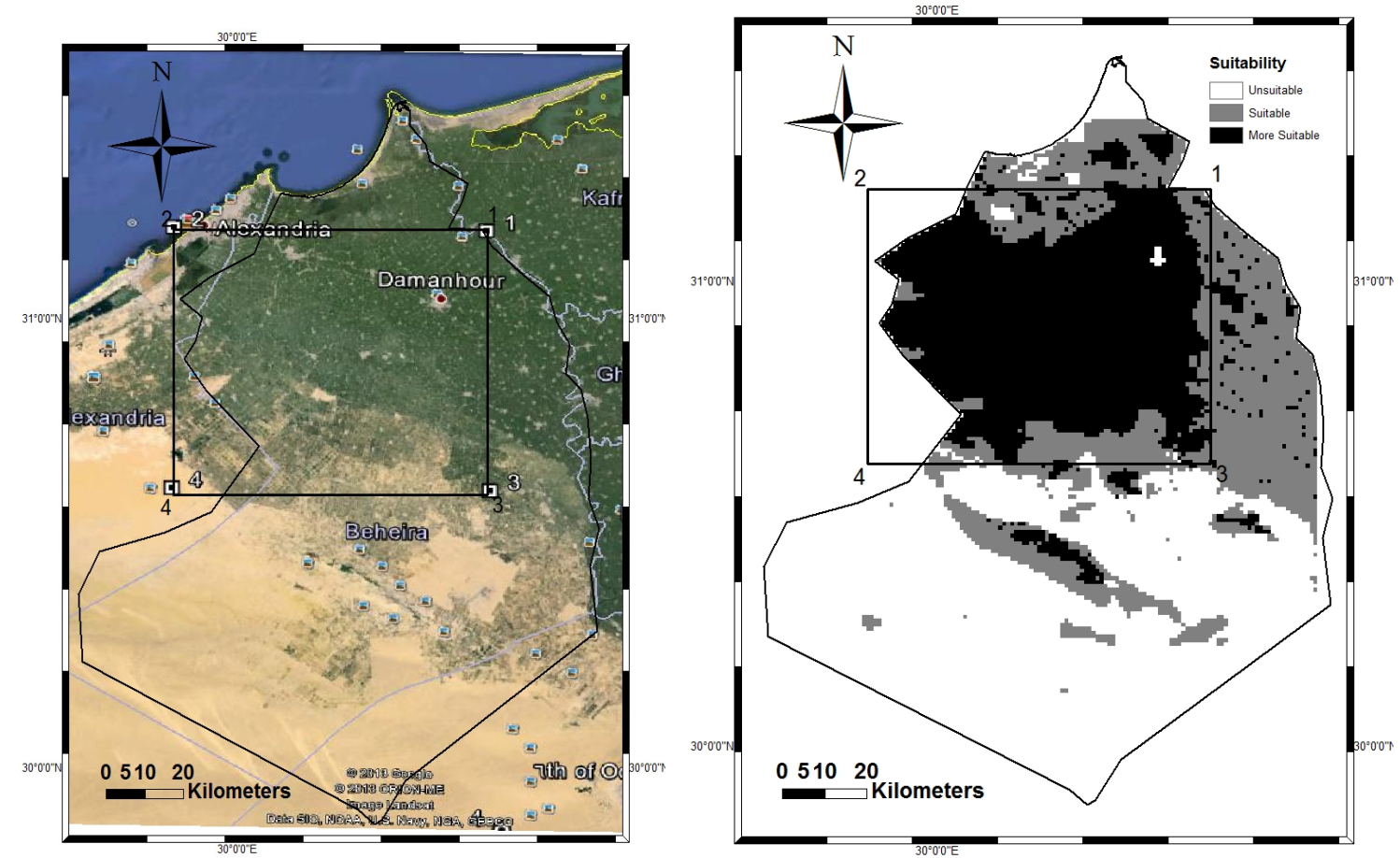

Fig.4. More suitable regions for colonies wintering were marked by a square in a google earth map (left) and in the wintering map (right). 
Table 3: Longitude $(\mathrm{X})$ and latitude (y) for 4 points cover the more suitable wintering regions in Decimal Degrees.

\begin{tabular}{|l|c|c|}
\hline Point & Longitude $(\mathbf{X})$ & Latitude $(\mathbf{y})$ \\
\hline $\mathbf{1}$ & 30.582 & 31.199 \\
\hline $\mathbf{2}$ & 29.851 & 31.197 \\
\hline $\mathbf{3}$ & 30.586 & 30.613 \\
\hline $\mathbf{4}$ & 29.847 & 30.609 \\
\hline
\end{tabular}

Fig.(5) shows the wintering map derived from factors at different weights. It is clear that the more suitable, suitable and unsuitable regions for colonies wintering derived from this map and from the previous map are approximately the same with some minor dissimilarities. Also, the square with aforementioned points were placed on the map to aperient the visual observation of the differences between the two maps.

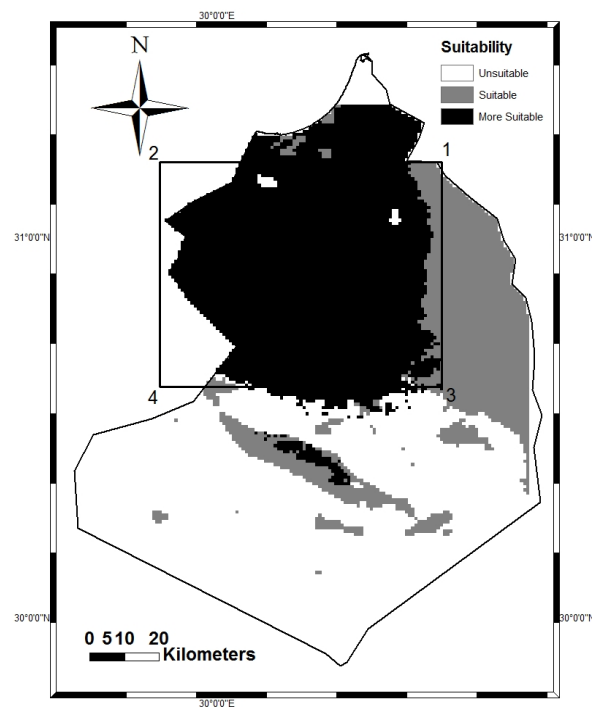

Fig.5. Wintering map for honey bee colonies derived from factors at different weights according to their relative importance.

The spatial statistical analysis for the wintering regions derived from the two maps, datasets at the same weight or at different weights (Fig. 6) shows the presence of significant differences between the more suitable regions and unsuitable regions while no suitable regions and most of the suitable regions. Approximately the same trend for significance distribution was detected in the two maps which reveals the absence of large differences between the significant differences were found between more two methods for creating the wintering maps.

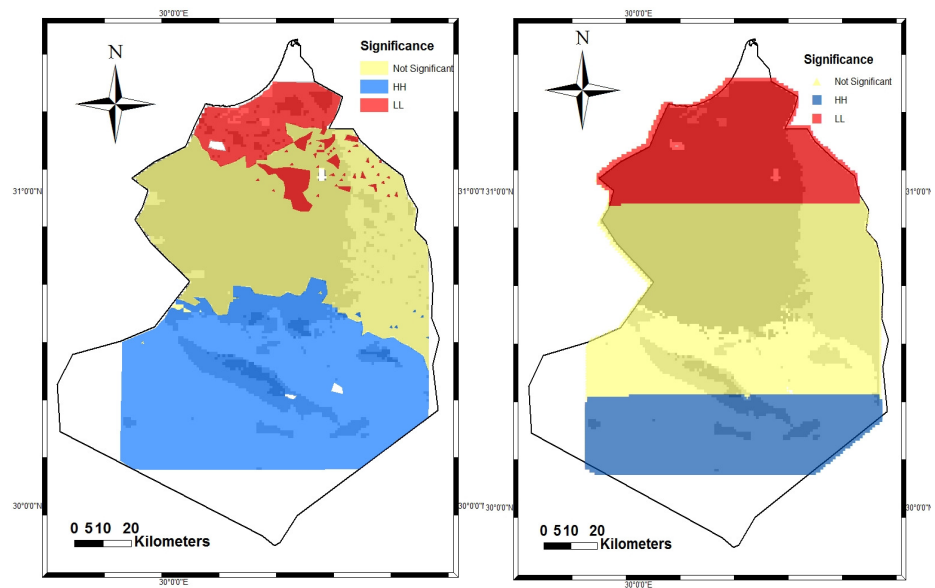

Fig.6. Significance of wintering regions (HH: significant regions of high values and LL: significant regions of low values) at 0.05 level of significance. Map derived from factors at the same weight (left) and at different weights (right). 


\section{DISCUSSION:}

Combining the datasets at the same weight or at different weights based on their relative importance presented approximately the same suitability classification for wintering regions. This may be due to the equal importance of the input datasets because the suitable wintering regions should locate at cultivated regions with good weather, low precipitation, near to plants and water resources as well as to roads beside the low slope of the land. The honey bee colonies can perform thermoregulation within their colonies to keep suitable microclimate conditions within the colonies (Kronenberg and Heller, 1982), and the selected factors, for more suitable and suitable wintering regions, can improve colonies wintering, save honey bee efforts during thermoregulation and reduce the colonies death rate.

The google earth map typically was fit with the output maps by visual observation where the more suitable regions were located at cultivated regions and near from water sources (Nile river and its streams) as well as near from the roads (these regions are located near to the cities). The far northern regions were generally classified as suitable for wintering and not as more suitable and that may be due to proximity location to the Mediterranean sea, which may impact the weather passively at these regions (i.e. low temperature and heavy rain fall). At the same time the southern regions were classified as unsuitable for wintering and that may be due to the desert nature and the far from roads and water sources as well as plants. The southern parts may be are more warm than the northern parts, however, the lacking of cultivated plants, road and water sources are critical limitations for wintering suitability. In general, the used model in the present study showed high accuracy in identifying the suitable wintering regions. This result is in line with the findings of Abou-Shaara et.al. (2013), who found a high degree of accuracy for a similar model employed for the identification of beekeeping suitability under harsh environmental conditions.

Conclusion: Creating wintering maps by using different datasets as used in the present study presented accurate results about the suitable regions for colonies wintering. No need for assigning specific relative weights and sufficiently combine the datasets at the same weight. For beekeepers, wintering of honey bee colonies in the southern or in the far northern regions is not recommended. The model described in the present study can be applied elsewhere and for the same purpose.

\section{REFERENCES:}

Abou-Shaara, H.F. (2012). Notes on water collection by honey bees. Bee World, 89 (4): 50-51.
Abou-Shaara, H.F. ; A.A. Al-Ghamdi and A.A. Mohamed (2013). A Suitability Map for Keeping Honey Bees Under Harsh Environmental Conditions Using Geographical Information System. World Appl. Sci. J., 22 (8): 1099 -1105.

Amiri, F. and A.B.M. Shariff (2012). Application of geographic information systems in landuse suitability evaluation for beekeeping: A case study of Vahregan watershed (Iran). Afr. J. Agri. Res., 7(1):89-97.

Amiri, F.; A.B.M. Shariff and S. Arekhi (2011). An Approach for Rangeland Suitability Analysis to Apiculture Planning in Gharah Aghach Region, Isfahan-Iran. World Appl. Sci. J., 12 (7): 962972.

Coulson, R.N.; M.A. Pinto; M.D. Tchakerian; K.A. Baum; W.L. Rubink and J.S. Johnston (2005). Feral honey bees in pine forest landscapes of east Texas. For. Ecol. Manage., 215: 91-102.

Erdogan, Y.; A. Dodologlu and B. Emsen (2009). Some physiological characteristics of honey bee (Apis mellifera L.) housed in heated, fan wooden and insulated Beehives. J. Anim. Vet. Adv., 8 (8): 1516-1519.

Estoque, R.C. and Y. Murayama (2010). Suitability analysis for beekeeping sites in La Union, Philippines, Using GIS and multi-criteria evaluation techniques. Res. J. Appl. Sci., 5(3): 242-253.

Hagler, J.R.; S. Mueller; L.R.Teuber; S.A. Machtley and A. Van Deynze (2011). Foraging range of honey bees, Apis mellifera, in alfalfa seed production fields. J. Insect Sci., 11:144.

Joshi, N.C. and P.C. Joshi (2010). Foraging Behaviour of Apis Spp. on Apple Flowers in a Subtropical Environment. New York Science Journal, 3(3): 71-76.

Kronenberg, F. and H.C. Heller (1982). Colonial thermoregulation in honey bees (Apis mellifera). J. Comp. Physiol. B, 148:65-76.

Myung-Hee, J.; K. Joon-Bum and B. Seong-Baek (2001). Selection technique for honey Plant complex area using landsat image and GIS. The $22^{\text {nd }}$ Asian Conference on Remote Sensing, 5- 9 November, Singapore.

Nguyen, B.K.; J. Mignon; D. Laget; D. de Graaf; F.J. Jacobs; D. vanEngelsdorp; Y. Brostaux; C. Saegerman and E. Haubruge (2010). Honey bee colony losses in Belgium during the 2008-9 winter. J. Apic. Res. \& Bee World, 49(4): 337339.

\section{HOSSAM F. ABOU-SHAARA}


Omran, N.S.M. (2011). Wintering of honeybee colonies (Apis mellifera L.) by using a new technique during winter season in Sohag region, Egypt J. Appl. Sci. Res., 7(2): 174-182.

Saaty, T.L. (2008). Decision making with the analytic hierarchy process. Int. J. Serv. Sci., 1(1): 83-98.

Spleen, A.M.; E.J. Lengerich; K. Rennich; D. Caron; R. Rose; J.S. Pettis; M. Henson; J.T. Wilkes; M. Wilson; J. Stitzinger; K. Lee; M. Andree; R. Snyder and D. vanEngelsdorp (2013). A national survey of managed honey bee 2011-12 winter colony losses in the United States: results from the Bee Informed Partnership. J. Apic. Res., 52(2): 44-53.
Tan, K.; S. Yang; Z. Wang; S.E. Radloff and B.P. Oldroyd (2012). Differences in foraging and broodnest temperature in the honey bees Apis cerana and A. mellifera. Apidologie, 43(6): 618623.

Zacepins, A. and E. Stalidzans (2012). Architecture of automatized control system for honey bee indoor wintering process monitoring and control. $13^{\text {th }}$ International Carpathian Control Conference (ICCC), p:772 -775. 